\title{
Knowledge-making distinctions in synthetic biology
}

\author{
Maureen A. O'Malley,* Alexander Powell, Jonathan F. Davies, \\ and Jane Calvert
}

\begin{abstract}
Summary
Synthetic biology is an increasingly high-profile area of research that can be understood as encompassing three broad approaches towards the synthesis of living systems: DNA-based device construction, genome-driven cell engineering and protocell creation. Each approach is characterized by different aims, methods and constructs, in addition to a range of positions on intellectual property and regulatory regimes. We identify subtle but important differences between the schools in relation to their treatments of genetic determinism, cellular context and complexity. These distinctions tie into two broader issues that define synthetic biology: the relationships between biology and engineering, and between synthesis and analysis. These themes also illuminate synthetic biology's connections to genetic and other forms of biological engineering, as well as to systems biology. We suggest that all these knowledge-making distinctions in synthetic biology raise fundamental questions about the nature of biological investigation and its relationship to the construction of biological components and systems. BioEssays 30:57-65, 2008.

(C) 2007 Wiley Periodicals, Inc.
\end{abstract}

\section{Introduction}

Synthetic biology takes its crucial adjective from the Greek sunthesis, $\sigma u ́ v \theta \varepsilon \sigma l \varsigma$, which means to put together or assemble. ${ }^{(1)}$ The current use of the term started in the late 1990 s, as attempts to construct functional modules began to make progress. ${ }^{(2)}$ Although the label 'synthetic biology' broadly refers to a rapidly growing scientific body of research with extensive funding and institutional support, the approaches that it covers are sufficiently different that an umbrella term conceals more than it reveals. Teasing out these differences is a valuable exercise because of the basic questions that synthetic biology raises about living systems and how to investigate them.

We identify three main categories of synthetic biology (see Table 1), each representing a particular approach to the construction of biological components: DNA-based device construction, genome-driven cell engineering, and protocell

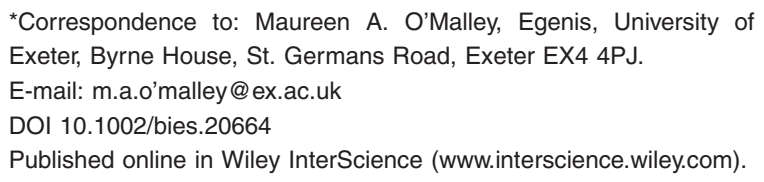

creation. Each category is associated with a range of views about the intellectual property issues raised by synthetic biology, and whether the field should be regulated by governments or by scientific communities. Most importantly, the categories reflect distinctive approaches to biological investigation, which can be characterized in terms of different attitudes towards genetic determinism, cellular context and complexity (in relation to concepts of modularity and emergence).

Some other schemes have divided synthetic biology into two camps: either on the grounds of in vivo or in vitro methods, ${ }^{(3)}$ or by a natural-unnatural distinction. ${ }^{(4)}$ We think, however, that the categorization that follows not only provides a better classification of the practices involved in synthetic biology, but also offers more insight into some of the underlying tensions between these approaches. Although it is sometimes possible to identify particular projects or researchers with feet in more than one camp, each category can readily be identified with specific lines of research and with a 'hard core' of researchers who act as spokespersons and motivators. From this point of view, the categories appear often to operate as semi-independent schools of research.

\section{Categories of synthetic biology}

DNA-based device construction

This first category is currently the most prominent and the most overtly programmatic in its approach. The technology of DNA synthesis, its fundamental tool, continues to develop rapidly in terms of both speed and fidelity. ${ }^{(3,5-7)}$ One of the key aims of this school is 'to make biology into an engineering discipline'. ${ }^{(8,9)}$ To achieve this, it emphasizes the mutual necessity of design and fabrication, which are iterative phases of manipulation directed towards implementing humandefined functions in engineered biological systems. ${ }^{(10)}$

Underpinning the primary aim of gaining full control of specified biological processes is the assumption that successful system building will require the reduction of biological complexity. The most-well-known formulation of how to achieve this has been disseminated by MIT's Drew Endy. ${ }^{(8)}$ He proposes a three-pronged approach of standardization, decoupling and abstraction. Standardization entails the definitive description and characterization of parts. Decoupling 
Table 1. Categories of synthetic biology

\begin{tabular}{|c|c|c|c|}
\hline & $\begin{array}{l}\text { DNA-based device } \\
\text { construction }\end{array}$ & $\begin{array}{c}\text { Genome-driven cell } \\
\text { engineering }\end{array}$ & Protocell creation \\
\hline Aims & $\begin{array}{l}\text { To transform biology into engineering; } \\
\text { To construct functioning biological } \\
\text { components from the bottom up }\end{array}$ & $\begin{array}{l}\text { To synthesize minimal but entire } \\
\text { genomes and insert them in cells; } \\
\text { To control cellular production } \\
\text { processes }\end{array}$ & $\begin{array}{l}\text { To construct viable approximations } \\
\text { of cells; To understand } \\
\text { non-synthetic biology and the } \\
\text { origin of life }\end{array}$ \\
\hline Methodological principles & $\begin{array}{l}\text { Design and fabricate; Engineering } \\
\text { principles; Bottom-up approach }\end{array}$ & $\begin{array}{l}\text { Bioinformatic-based engineering } \\
\text { combining bottom-up and top-down } \\
\text { strategies }\end{array}$ & $\begin{array}{l}\text { Intermediate and bottom-up } \\
\text { approaches; Theoretical } \\
\text { modelling and experimental } \\
\text { construction }\end{array}$ \\
\hline Techniques & $\begin{array}{l}\text { Synthesis of DNA devices and } \\
\text { insertion in cells }\end{array}$ & $\begin{array}{l}\text { Bioinformatic analysis of genome, } \\
\text { genome engineering, and insertion } \\
\text { in living cells }\end{array}$ & $\begin{array}{l}\text { Construction of rudimentary cells } \\
\& \text { cellular sub-systems, using } \\
\text { synthesized and existing } \\
\text { components }\end{array}$ \\
\hline Constructs and exemplars & $\begin{array}{l}\text { Toggle switch; Repressilator; } \\
\text { Artemisinin metabolic pathway }\end{array}$ & $\begin{array}{l}\text { Viral genome synthesis; } \\
\text { 'Transformation' of organism/ } \\
\text { species via genome replacement }\end{array}$ & $\begin{array}{l}\text { Containers such as micelles and } \\
\text { vesicles with genetic \& } \\
\text { metabolic components }\end{array}$ \\
\hline $\begin{array}{l}\text { Interactions with other } \\
\text { approaches }\end{array}$ & $\begin{array}{l}\text { Components for minimal cells } \\
\text { and protocells }\end{array}$ & $\begin{array}{l}\text { New DNA synthesis techniques; } \\
\text { Cellular platforms for device } \\
\text { insertion }\end{array}$ & $\begin{array}{l}\text { Essential genes and biochemical } \\
\text { systems for cellular life; } \\
\text { Chassis }\end{array}$ \\
\hline $\begin{array}{l}\text { Intellectual property } \\
\text { agenda }\end{array}$ & $\begin{array}{l}\text { Open source at parts level; } \\
\text { Proprietary at network level for } \\
\text { methods and systems }\end{array}$ & $\begin{array}{l}\text { Open source at a general bioinformatic } \\
\text { level; Proprietary in relation to a } \\
\text { specified minimal genome and the } \\
\text { replicating organism }\end{array}$ & $\begin{array}{l}\text { Standard data-sharing } \\
\text { mechanisms (i.e.: publication); } \\
\text { Patents and companies focused } \\
\text { on methods }\end{array}$ \\
\hline Regulation position & $\begin{array}{l}\text { Scientific community should } \\
\text { regulate itself }\end{array}$ & $\begin{array}{l}\text { Consultation with outside experts } \\
\text { and some of engagement in public } \\
\text { discussion }\end{array}$ & $\begin{array}{l}\text { Low-key in-house discussion re } \\
\text { risks; Minority: Need for some } \\
\text { governmental regulation }\end{array}$ \\
\hline
\end{tabular}

is the process of breaking down the construction of complicated entities into manageable semi-independent tasks. Abstraction is about the identification of hierarchies of functional units, chiefly in order to facilitate the design process. The abstraction of 'DNA, parts, devices and systems' is the one in common use at present. ${ }^{(11)}$

Thinking of parts and devices as practically independent of the systems in which they occur is part of the commitment to standardization. As in other engineering fields, components must be interchangeable, functionally discrete and able to be combined easily in a modular fashion. ${ }^{(8,12)}$ To this end, a major effort is under way to set up an open-access library of presynthesized biological parts and devices, the Registry of Standard Biological Parts. ${ }^{(13)}$ These components, commonly called 'BioBricks', can be assembled to form more complex biological devices, such as oscillators, which function in modified cells.

The majority of components in these synthesizing efforts are made from engineered gene circuits that tailor proteinDNA interactions to control transcription, ${ }^{(14,15)}$ although some use RNA components to regulate gene expression and control cellular function. ${ }^{(16)}$ Paradigmatic examples of DNA-based constructs include the toggle switch ${ }^{(17)}$ and 'repressilator' network. ${ }^{(18,19)}$ The creation of 'toys' has been a focus of much device-oriented synthesis, as attested to by the annual international Genetically Engineered Machine jamboree (iGEM). Examples include bacteria able to play noughts- and-crosses, ${ }^{(20)}$ a cell-based digital counting device ${ }^{(21)}$ and image-processing capabilities in an E. colicolony. ${ }^{(22)}$ Although these constructions are not frivolous, a more 'serious' and much publicized achievement has been the engineering of part of the metabolic pathway for the therapeutic product of artemisinin. ${ }^{(23,24)}$

While all the BioBricks are freely available, components that function in cellular contexts-such as the artemisinin pathway-have been patented as methods, ${ }^{(25)}$ and companies with strong IP protection policies (e.g. Codon Devices, Amyris) have been founded to supply engineered DNA constructs and their products. There are deep economic tensions between these two ownership strategies and some attention is being directed towards how they might be reconciled. ${ }^{(26,27)}$ To further complicate the IP arena, few of these synthetic biologists anticipate the development of commercial applications within the next decade. ${ }^{(28)}$ This school of synthetic biology has been very forthright in its arguments for self-regulation, and synthetic biology conferences that have showcased projects from this group have made considerable efforts to advance in-house discussion of regulatory needs and safeguards. ${ }^{(29-31)}$

\section{Genome-driven cell engineering}

The second category of synthetic biology works at the wholegenome level and uses both top-down strategies (starting with the genome) and bottom-up strategies (starting with

\section{BioEssays $\mathbf{3 0 . 1}$}


nucleotides) to conduct minimal genome analysis, wholegenome synthesis and the transplantation of 'foreign' or modified genomes into cells. We place all these activities into one category because of the whole-genome focus and because of the way in which members of this group tend to see genomes as the causal engines of the cell. Minimal genomics (sometimes placed by other commentators in what we think is a third category with different practices and underlying aims) entails the deletion of non-essential genes to streamline cellular componentry and make room for synthetic DNA constructs. ${ }^{(32-34)}$ It aims to create a simple standardized host cell or 'chassis' that would make device implantation more predictable and effective. A precursor project involving viral genome redesign is Chan and colleagues' 'refactoring' of the T7 phage, in which wild DNA was replaced by synthetic DNA in order to create a more modularized genome and a more manipulable phage. ${ }^{(35)}$ Another project successfully reduced the E. coli genome by $15 \%$. $^{(32)}$

The bottom-up synthesis of viral genomes is also making advances, as exemplified by Cello and colleagues' de novo chemical synthesis of a poliovirus genome, which exhibited the same infectious capacity as a natural virus when put in a cellular context. $^{(36)}$ The genome of the $\Phi 174$ phage was synthesized from commercially available synthetic oligonucleotides in just two weeks. ${ }^{(37)}$ Craig Venter's team at SyntheticGenomics hopes eventually to synthesize an entire bacterial genome and make it work in a synthetic cell. ${ }^{(38)}$ Venter believes they are well on the way to this aim with the apparently successful transplantion of a 'natural' genome from one species of Mycoplasma to another, ${ }^{(39)}$ although it is not known what mechanisms were involved in the genome replacement and there is some scepticism about whether whole-genome transplanations will be viable in more experimentally robust prokaryote cells. ${ }^{(40,41)}$ Other less complete genome transplantation projects using different organisms illustrate alternative cell 'rebooting' techniques. ${ }^{(42,43)}$

Some of the genome-driven strands of research appear to be highly instrumental in their approach to biological synthesis, consistent with the aim of developing biological technology rather than acquiring biological knowledge for its own sake. Nonetheless, such research makes important contributions to the conceptually intriguing and biologically fundamental question about the minimal genomic basis for sustaining cellular life. Many efforts in this branch of synthetic biology have attracted a great deal of public attention regarding both biosecurity risks and commercialization concerns, especially following Synthetic Genomics' application for a very broad patent on a minimal genome and any organism that replicates it. ${ }^{(44-46)}$ In an attempt to dispel some of these worries, this particular research team has consulted with external ethics experts in relation to synthetic genome projects and been given an ethical green-light for various projects. ${ }^{(47,48)}$

\section{Protocell creation}

The third category of synthetic biology aims to construct minimal cellular systems. It is often related to earlier work such as Stanley Miller's 1953 experiment addressing the question of how life might have originated from simple inorganic compounds. ${ }^{(49)}$ The bottom-up strategy for the construction of minimal cells starts by synthesizing the basic molecular components necessary for a self-replicating biosystem and then inserts that system into compartments such as vesicles ${ }^{(50-53)}$ or develops it in vitro. ${ }^{(54)}$ An associated 'intermediate' strategy (neither top-down nor bottom-up, but 'reconstructive') involves a 'semi-synthetic' approach in which extant genes and enzymes are put into vesicles (often liposomes) to produce 'semi-artificial' cells. ${ }^{(55)}$ All this research involves a great deal of theoretical modelling, which attempts to capture underlying principles of cellular dynamics and molecular self-assembly in order to guide experimental work more effectively. ${ }^{(52)}$

The issues of what life is and where the transition from nonlife to life occurs are frequently discussed by members of this category. ${ }^{(53)}$ They sometimes suggest that their focus on fundamental biological properties-such as metabolism, genome replication, cell division and the capacity for evolution-distinguishes protocell synthetic biology from the other two categories. ${ }^{(52)}$ Certainly, the attribution of causal equality to membranes, metabolism and genetic information (rather than seeing cellular events as directed by the latter) sets this school apart from the other two. Another important factor is the school's explicit use of novel or modified natural systems to test and improve theoretical models of biological phenomena. For this reason, and also because of their interest in the evolution of emergent properties of biological systems, we could at least partly include in this category researchers whose focus on DNA-based synthetic biology might otherwise indicate their placement in the first category. ${ }^{(56,4)}$

Protocell synthetic biologists have yet to come under particular public scrutiny, perhaps because they have been somewhat sidelined by the recent institutionalization of the two other categories of synthetic biology. At least one company has been formed by protocell researchers ${ }^{(57)}$ although patenting activity associated with scientists in this category does not relate to protocell constructs but to more general methods, including those of DNA synthesis. There is little ethical or regulatory discussion amongst these researchers at present. ${ }^{(58)}$ George Church, whose chassis work best fits this category despite his strong links to the DNA-based devices school, subscribes to a minority position on regulation, which acknowledges the need for government monitoring of device distribution. ${ }^{(59)}$

\section{Epistemological dynamics in synthetic biology}

Our three-fold categorization represents an idealized framework that should not be thought of as static. Interactions between the different approaches give rise to a complex network of inter-relationships and mutual dependencies. DNA- 
based device construction is able to supply a variety of components to the other approaches. Protocell work generates potential chassis for DNA and genome-based engineering. And those working on genome synthesis and minimal genome analysis are already developing new DNA synthesis methods as well as platforms for further cell-based work. In addition to all this interchange, some distinctions can be made regarding how each group conceives of its activities. While Table 1 represents how synthetic biology could be characterized by approach and with respect to the methods and materials most commonly used, what is probably of more interest are the abstract relationships between each school and how dynamic tensions are maintained amongst the three groups (see Fig. 1). We focus on how these categories are positioned in relation to genetic determinism and their treatments of cellular context and biological complexity.

\section{Genetic determinism}

A defining assumption of the genome-driven cell-engineering approach is that the genome is the major determinant of cellular events. This is most obvious in genome transplantation work, but also in associated research. At the meeting Synthetic Biology 3.0, Miroslav Radman noted the apparent revival of a DNAcentric view of life, and related it to the idea that if a functional genome can be reconstituted then life can be 'resurrected'. (60) Protocell synthetic biologists, on the other hand, see causal power as being shared more equally by the genome, cytoplasmic structures and cell membranes. Nevertheless, they use DNA instrumentally in order to generate and support desired cellular activities, and the same can of course be said of the DNA-based devices school but with greater force. For the latter group, any tendencies towards straightforward genetic determinism are overridden by its conviction about the modular unity of functionally defined parts.

\section{Cellular context}

Implicit in the strong genetic determinism characteristic of genome-driven cell engineering is the idea that cellular context

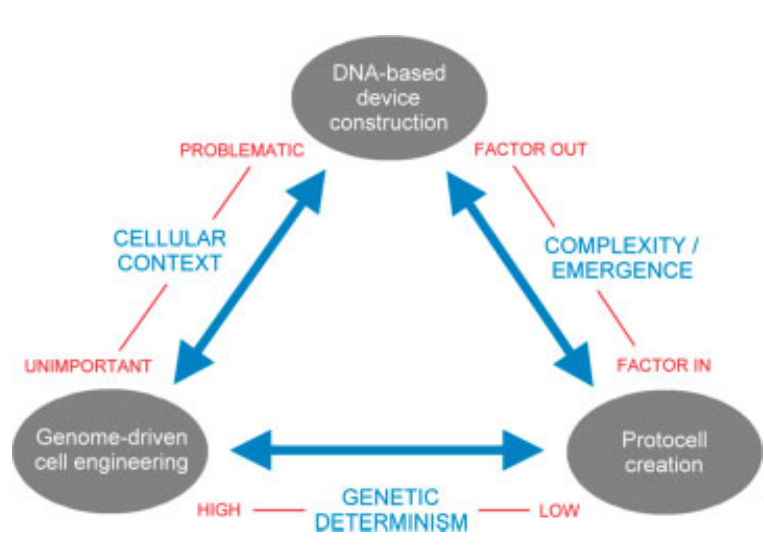

Figure 1. Epistemological dynamics in synthetic biology. is relatively unimportant. This idea is associated with a family of views, ranging from the classically reductionist (genes have functions, and when the relevant genes are put into cells, their functions are implemented) to the more holistic (whole genomes give rise to interrelated sets of functions). Chassis production, some of which we placed in the protocell category, is clearly an attempt to minimize and control contextual influences on inserted componentry. The DNA-based device construction school's focus on modularity, however, makes a more explicit statement that what a component does-the function with which it can be identified — can be separated from its environmental influences.

Functional independence or modularity is often an underlying necessity for engineering approaches to biology. ${ }^{(61-63)}$ Often, in DNA-based device construction, modularity is taken for granted as an omnipresent property of biological parts. Sometimes, however, the concept is deployed as a methodological tool for making biological complexity comprehensible. Endy hints at this when he says, 'there is no apparent organization or hierarchy to most naturally evolved genetic systems', ${ }^{64)}$ and Open Wetware explicitly adopts the position that abstraction hierarchies are a human invention. ${ }^{(65)}$ Not all of this school are convinced that this is the best interpretation of modularity, however. There is a recognition that function is defined by context and that, in many instances, designations of modularity are hypotheses to be tested. ${ }^{(12,66)}$ As synthetic biology expands into the construction of more complex functions (i.e. metabolic), and thereby increases the behavioural diversity of interacting components, more knowledge of cellular context will inevitably be demanded. ${ }^{(67-69)}$

\section{Complexity and emergence}

Both tensions above find their conceptual roots in the larger issue of biological complexity. The protocell school emphasizes the capacity of cell components to self-assemble and self-organize, and much of its research focuses on properties related to the fluidity of the cellular environment. ${ }^{(52,70)}$ For these reasons, the possibilities for complex dynamics and emergent phenomena tend to be seen as topics for explicit investigation, with a view to harnessing them to create novel systems with recognizably biological properties. This is also the case for the DNA synthesizers who emphasize chemical synthesis rather than engineering and hold the recreation of emergent properties to be their overarching goal. ${ }^{(4)}$

The DNA-based devices school takes a far less accommodating approach towards biological complexity, reflecting its engineering bias in favour of construction over comprehension. Complexity is conceived of as something to be reduced. ${ }^{(69,71,72)}$ As one of the school's spokespersons, Tom Knight, puts it, 'An alternative to understanding complexity is to get rid of it'. ${ }^{(73)}$ This stance is not necessarily the product of a lack of sophistication, however. Rather, engineering principles and the simplification programme can be seen as representing

\section{BioEssays 30.1}


an acknowledgement that biological knowledge is incomplete, and that the uncertainties must be factored out (by means of standardized parts and chassis) to enable the design of systems with pre-determined properties and functions. ${ }^{(8,74)}$ In contrast to the general assumption that the properties and behaviour of components straightforwardly predict the properties and behaviour of the larger and more complex systems that they constitute, ${ }^{(75)}$ some members of this school acknowledge the limitations of too strict an adherence to the engineering analogy and are seeking new lines of insight into the synthesis of complex system behaviour. ${ }^{(76)}$

Whilst the engineering-led simplifications of the DNAbased devices school can appear 'unbiological', it should not be thought that protocell workers necessarily confront biological complexity more directly. Frequently they too work with heavily simplified systems in order to address particular questions and investigate specific aspects of phenomena. Protocell constructs can also be viewed as expansions of the experimental use of vesicles and other compartments in more traditional research that sought simply to create membrane models or deliver biomolecules to cells. ${ }^{(77)}$ Overall, however, the third school's less explicit focus on the creation of novel function in favour of developing a deeper understanding of the distinctively biological properties of matter aligns their style of simplification much more closely with traditional analytical scientific approaches.

\section{Broader relationships and interactions}

The distinctions discussed so far have been internal to synthetic biology. As well as being distinguishable by their approach to synthesis, schools of synthetic biology raise more general epistemological issues, about the relationship of biology to engineering, and synthesis to analysis. These themes have a bearing on synthetic biology's relationship to other fields, such as genetic and other forms of bioengineering, and systems biology. Clarifying these relationships enables a better understanding of synthetic biology in relation to molecular biology and biological investigation more broadly.

\section{Biology versus engineering}

Several synthetic biologists quote physicist Richard Feynman in order to establish a foundation for their claims about the importance of construction: 'What I cannot create I do not understand'. ${ }^{(78,69)}$ The Feynman dictum is most strongly expressed by the DNA-based devices school, in which the ultimate objective is to make biology into an engineering discipline. ${ }^{(9,71,79)}$ While scientists may once have thought of engineering as a lower-status activity, in this category of synthetic biology we see an inversion of the hierarchy, with some synthetic biologists wishing to be perceived primarily as engineers. ${ }^{(80)}$

Biology and engineering are often distinguished in terms of their objects and modes of practice. While biology investigates systems produced by evolution, engineering produces systems for particular purposes. ${ }^{(10)}$ Outside the software realm engineers characteristically assemble stable, highly constrained structures. Typically these are realised through or bounded by solid-state parts that tend to be chemically inert. Biological systems, in contrast, exploit a range of states, with fluidity playing a fundamental role. At the molecular scale, biological components thus have many degrees of freedom and, in addition, chemical interactions are a significant influence on events. The apparent stability of cellular structures is largely an illusion, achieved by the turnover of matter through a variety of mechanisms and at widely varying rates. The approaches employed within biology and engineering are as distinctive as their objects: biology is directed towards discovery whereas engineering is concerned with design. ${ }^{(81)}$ We have seen how the instrumental objectives of engineering mean that its attitude to complexity has to be very different from that found more generally in biology. Engineers often aspire to streamline complexity and to bypass it when practical. ${ }^{(82,64)}$

This drive towards simplicity appeared to sacrifice the possibility of attaining a deep understanding of contextual influences on parts, their evolved variability and the relationship of context and variation to functional properties. That sacrifice contributes to a central tension in synthetic biology, between construction and comprehension. Although this issue is relevant to the entire field, we see it as being especially prominent in the energetically promoted engineering-oriented approaches, in which we include the category of DNA-based device construction as well as much genome-driven cell engineering.

Genetic, protein, metabolic and nano-engineering. Although DNA-based device construction in particular appears to share many features with genetic engineering, a number of those in the field claim that these similarities are superficial for several reasons. The creators of the toggle switch in $E$. coli claim that their construction is a 'significant departure from genetic engineering' because it manipulates overall network architecture and not just specific proteins or regulatory elements. ${ }^{(17)}$ Genetic engineering is often depicted as a hit-and-miss activity, involving hardly any 'real' engineering. ${ }^{\left({ }^{83}\right)}$ Proponents of this school of synthetic biology argue that their work, by contrast, is as much about design as fabrication, and its strategies and methodologies are more formalized in both phases, ${ }^{(63)}$ even though luck and 'debugging'-by, for example, the application of directed evolution to designed but non-functional circuits $^{(84)}$ _play major roles in determining whether inserted devices work or not. ${ }^{(85,86)}$

A major distinction between this category of synthetic biology and 'ordinary' genetic engineering is often made on the grounds of contextualization and complexity. Genetic engineering is said to be defined by its limited consideration of 
context, unlike DNA-based device construction, which is held to be deeply context-oriented. ${ }^{(12,10)}$ Context certainly matters for engineering-oriented synthetic biology, but primarily for practical reasons: it might stop devices working. Our discussion above of context and complexity in relation to the engineering schools and their emphasis on the independence of parts makes this claim about context a less than compelling one.

We think that the distinctions made by synthetic biologists do not clearly delineate the first two categories of synthetic biology from earlier practices of genetic engineering. At least part of the motivation for distinguishing synthetic biology from genetic engineering may come from both the DNA-based and genome-driven communities' hopes to avoid both public controversy and external regulation. Ethical concerns about and public reactions to synthetic biology projects are likely to be very similar to those directed at the genetic engineering of crops and other organisms. ${ }^{(73,87)}$ It is clear that, although all three categories of synthetic biology are tinkering with living systems, rhetoric, profile and commercialization strategy all influence the amount of public opposition. The protocell community is left somewhat out in the cold in this debate, which is perhaps puzzling given us greater attention to what might be deemed 'life' and 'non-life'.

A wider motivation in making such distinctions no doubt lies in discipline-building attempts. The substantial overlap between synthetic biology and protein and metabolic engineering leads some commentators to list the latter two under the allegedly broader heading of synthetic biology. ${ }^{(79,81)}$ Incorporation may not properly describe the relationships between these approaches, however. There is considerable continuity in the aims of most bioengineering and synthetic biology, and synthetic biology may just be an extension of these older projects: they certainly share the ambition to create novel functions by engineering biological material. It might be more appropriate to view synthetic biology as providing a broad set of genetically based tools that have the potential to underpin further achievements in more biologically defined approaches, such as metabolic engineering. ${ }^{(88)}$

Nanobiotechnology also maintains an ambivalent relationship with synthetic biology. It is sometimes thought of as augmenting synthetic biology, even though integrating nanomaterials into biological systems is a major hurdle still to be overcome. ${ }^{\left({ }^{89}\right)}$ However, synthetic biology could just as easily be conceived of as a tool for nanobiotechnology. ${ }^{(67)}$ It is curious that discussions of nanobiotechnology, which might be thought of as the ultimate engineering approach, should involve such fundamental discussions of biological self-organization and the boundaries of naturalness even at these early stages of the field's development. ${ }^{67,89)}$ Perhaps part of the explanation lies in nanoengineers' awareness of physical and chemical properties that obtain at the molecular but not the macroscopic scale. ${ }^{(89)}$
Synthesis versus analysis

Synthesis has two meanings in synthetic biology: fabrication and integration. The first meaning is the most commonly employed one but the second is brought out very clearly when synthetic biology is being compared to analytic biology. A major distinction is often made, for example, between conventional molecular biology and synthetic biology with the declaration that the latter's mode of inquiry stresses design and synthesis rather than discovery and analysis. This emphasis is meant to confer on synthetic biology the potential to achieve levels of scientific insight that elude traditional approaches. ${ }^{(4)}$ If this is so, it will presumably be because the design of functional systems necessarily involves considering interactions among parts that are situated in particular contexts. However, the constant singling-out of the individual properties of parts by all categories of synthetic biology demonstrates that analytic practices are just as much in the foreground of synthetic biology as are synthesizing strategies. One of the most obvious examples is a frequently employed self-description of some DNA-based device constructors: 'making life better, one part at a time' ${ }^{(90)}$ And, clearly, synthetic biology in general would not be possible without the knowledge base delivered by so-called analytic approaches.

\section{Systems biology}

The relationship between systems biology and synthetic biology closely reflects the synthesis/analysis distinction as well as their mutuality in any biological research. Synthetic and systems biology have each developed over the same period of intensive scientific activity (2000 onwards) and they overlapvia modelling especially-at the crucial interface of system design and quantitative analysis of function. ${ }^{(10)}$ They both focus on systems, rather than on particular genes or proteins. ${ }^{(12)}$ Both frequently represent cellular processes in terms of circuits and networks, and both aim ultimately at the prediction and control of biological systems. In the reciprocal interaction between the two, synthetic biology's design and construction phases require knowledge of the system as a whole, and knowledge from the fabrication process enhances system-level understanding. ${ }^{(14,81,91)}$ Synthetic biology can, from this perspective, be conceived of as 'the other side of the coin of systems biology'. ${ }^{(82)}$ Certainly, in a historical sense, systems biology and its endorsement of engineering perspectives $^{(92)}$ appears to have channelled broader support into synthetic biology.

There are important differences, however, between the two fields. Modelling in systems biology is sometimes distinguished on the grounds that it is for basic research (i.e. generating knowledge) whereas synthetic biology's modelling is for the design of constructs. ${ }^{(79)}$ The acquisition of comprehensive omic datasets is an absolute requirement for systems biologists, whereas all categories of synthetic biology are oriented towards the simplification of total informa-

\section{BioEssays $\mathbf{3 0 . 1}$}


tion. ${ }^{(82,72)}$ Large-scale data integration, an imperative for systems biology, is not necessarily on synthetic biology's agenda even though it does premise its activities on the need ultimately to integrate parts and devices to form functional wholes. Furthermore, whereas systems biology embraces complexity, synthetic biology (as we discussed above) is for many practitioners in our first two categories an attempt to do the opposite. Some even boast of ambitions to be 'a reductionist approach to systems biology'. ${ }^{(72)}$ In today's biology, with its emphasis on integration and anti-reductionism, and a corresponding willingness to talk about complexity and emergence, professing such attitudes might seem out of step with the way in which mainstream biology conceives of its agenda.

\section{Conclusion}

The epistemological differences that we have outlined can be broadly thought of under the tension of 'means versus ends' biology. Traditionally, biology has employed a range of strategies (means) to reach an end of better understanding. The first two categories of synthetic biology tend to collapse the means-ends distinction, so that their means (construction as a biological tool) becomes the end. We have noted how the ability to make something has come to represent a kind of epistemic 'gold standard' for engineering-oriented synthetic biologists. ${ }^{(8)}$ Although we might want to question the truth of Feynman's statement-he presumably thought that we had some understanding of the cosmos, even though we cannot create it-it is generally taken for granted within the most prominent school of synthetic biology and could be thought to implicitly inform our second category (which tends not to articulate more general justifications for its research).

This emphasis on synthesis-as-construction involves a major shift in how biological investigation is generally conceived. Biology has seldom been primarily about knowing-as-making but about gathering and integrating details of why nature works in particular ways. Traditionally, this has proceeded on the basis of mechanistic inquiry, in which systems are broken into parts but then pieced back together again as interactions and causal relationships between parts are understood. Synthetic biology for the most part fits the first phase of this mode of inquiry, but appears to transform the second phase into equating or substituting construction for understanding.

The theoretical biologist Robert Rosen, once neglected but now the subject of much attention in systems biology, concluded in his discussion of living systems that reductively mechanistic non-complex understandings of biology would 'literally kill life'. ${ }^{(93)} \mathrm{He}$ would no doubt have found much engineering-oriented synthetic biology epistemologically untenable, due to its systematic reduction of complexity and focus on biomolecular components. For him, as well as many contemporary biologists, understanding living systems as the operation of mechanical devices within organismal machines is something radically different from, and inadequate for, a relational understanding of biological systems as complex self-organizing entities. A few system-oriented biologists today believe that contemporary advances in data and modelling capabilities enable progress along the lines at which Rosen hinted. ${ }^{(94,95)}$

Given the variety of broader movements towards increasingly integrated understanding of complex biological systems, it seems far from inevitable that synthetic biology's engineering approaches will ever generally serve as substitutes for biological investigation. They could just as easily be conceived of as providing biology with a range of tools to collect more data and broaden understanding by construction, and with ways of testing and extending our knowledge of the properties of entities by studying their behaviour in a variety of contexts. Instead of being an end, the production of unnatural functions by engineering can be framed as a profound question about biological plasticity and how our understanding of natural phenomena can be extended. ${ }^{(4,67)}$

The fate of synthetic biology hinges on its capacity to deal with the complex properties of highly variable biological systems. The reduction of complexity may be necessary for proximate understanding, but it is a very limited manifesto for a field aspiring to be a new approach to biology. If synthetic biology's future is to be more than a modest contributor to 'analytic' biology, it needs to develop broader engineering principles that do more than mimic those of non-biological engineering. Uncritical acceptance of the strongly programmatic statements being made about the field is unlikely to further such advances. Our analysis has shown the many differences in approach that have gathered under the banner of synthetic biology. The main source of unity for this diverse collection of techniques and aims is that label itself, its promotional rhetoric and even the dissent it attracts.

\section{Acknowledgements}

Many thanks to Evelyn Fox Keller for stimulating our interest in synthetic biology, and to John Dupré and our anonymous reviewers for comments. We are especially grateful to Adam Wilkins, who provided exceedingly helpful editorial advice. Funding acknowledgements are due to the UK's Arts and Humanities Research Council (MO and JD), the Economic and Social Research Council (JC) and the University of Exeter for graduate student support (AP). The research for the paper was done as part of the programme of the ESRC Centre for Genomics in Society (Egenis), based at the University of Exeter.

\footnotetext{
References

1. Soames C, Stevenson A, editors. 2004. Concise Oxford English Dictionary, 11th edn. Oxford: Oxford University Press.
} 
2. Hartwell JH, Hopfield JJ, Leibler S, Murray AW. 1999. From molecular to modular cell biology. Nature 402:C47-C52.

3. Forster AC, Church GM. 2007. Synthetic biology projects in vitro. Genome Res 17:1-6.

4. Benner SA, Sismour AM. 2005. Synthetic biology. Nat Rev Genet 6:533543.

5. Stähler P, Beier M, Gao X, Hoheisel JD. 2006. Another side of genomics: synthetic biology as a means for the exploitation of whole-genome sequence information. J Biotechnol 124:206-212.

6. Kodumal S, Patel KG, Reid R, Manzella HG, Welch M, Santi DV. 2004. Total synthesis of long DNA sequences: synthesis of a contiguous 32-kb polyketide synthase gene cluster. Proc Natl Acad Sci USA 101:1557315578.

7. Tian J, Gong H, Sheng N, Zhou X, Gulari E, et al. 2004. Accurate multiplex gene synthesis from programmable DNA microchips. Nature 432:1050-1054

8. Endy D. 2005. Foundations for engineering biology. Nature 438:449-453.

9. e.g.: www.synberc.org/thrusts.html.

10. Brent R. 2004. A partnership between biology and engineering. Nat Biotechnol 22:1211-1214

11. http://parts.mit.edu/registry/index.php/Part_Types.

12. Andrianantoandro E, Basu S, Karig DK, Weiss R. 2006. Synthetic biology: new engineering rules for an emerging discipline. Mol Syst Biol DOI: $10.1038 / \mathrm{msb} 4100073$.

13. http://parts.mit.edu.

14. Drubin DA, Way JC, Silver PA. 2007. Designing biological systems. Genes Dev 21:242-254.

15. Sprinzak D, Elowitz MB. 2005. Reconstruction of genetic circuits. Nature 438:443-448.

16. Isaacs FJ, Dwyer DJ, Collins JJ. 2006. RNA synthetic biology. Nat Biotechnol 24:545-554.

17. Gardner TS, Cantor CR, Collins JJ. 2000. Construction of a genetic toggle switch in Escherichia coli. Nature 403:339-342.

18. Elowitz MB, Leibler S. 2000. A synthetic oscillatory network of transcriptional regulators. Nature 403:335-338.

19. Chen M-T, Weiss R. 2005. Artificial cell-cell communication in yeast Saccharomyces cerivisiae using signalling elements from Arabidopsis thaliana. Nat Biotechnol 23:1551-1555.

20. Stojanovic MN, Stefanovic D. 2003. A deoxyribozome-based molecular automaton. Nat Biotechnol 21:1069-1074.

21. Check E. 2005. Designs on life. Nature 438:417-418.

22. Levskaya A, Chevalier AA, Tabor JJ, Simpson ZB, Lavery LA, et al. 2005. Engineering Escherichia coli to see light. Nature 438:441442

23. Martin VJJ, Pitera DJ, Withers ST, Newman JD, Keasling JD. 2003. Engineering a mevalonate pathway in Escherichia coli for production of terpenoids. Nat Biotechnol 21:796-802.

24. Ro D-K, Paradise EM, Ouellet M, Fisher KJ, Newman KL, et al. 2006. Production of the antimalarial drug precursor artemisinic acid in engineered yeast. Nature 440:940-943.

25. Keasling J, Vincent M, Pitera D, Kim S-W, Withers S, et al. 2007. (Inventors); Regents of the University of California (Assignee). September 1. Biosynthesis of isopentenyl pyrophosphate. United States patent application 20070166782.

26. Henkel J, Maurer SM. 2007. The economics of synthetic biology. Mol Syst Biol 3:117. DOI: 10.1038/msb4100161.

27. Rai A, Boyle J. 2007. Synthetic biology: caught between property rights, the public domain, and the commons. PLoS Biol 5:e58. doi:10.1371/ journal.pbio.0050058.

28. Bio-Economic Research Associates. 2007. Genome synthesis and design futures: implications for the US economy. Cambridge, MA: BioEconomic Research Associates.

29. http://syntheticbiology.org/SB2.0/Biosecurity_resolutions.html.

30. Maurer SM, Lucas KV, Terrell S. 2006. From understanding to action: community-based options for improving safety and security in synthetic biology. University of California, Berkeley: Goldman School of Public Policy http://gspp.berkeley.edu/iths/Maurer\%20et\%20al. April\%203.pdf

31. Bügl H, Danner JP, Molinari RJ, Mulligan JT, Park HO, et al. 2007. DNA synthesis and biological security. Nat Biotechnol 25:627-629.
32. Pósfai G, Plunkett G III, Fehér T, Frisch D, Keil GM, et al. 2006. Emergent properties of reduced-genome Escherichia coli. Proc Natl Acad Sci USA 312:1044-1046.

33. Gil R, Silva FJ, Peretó J, Moya A. 2004. Determination of the core of a minimal bacterial gene set. Microbiol Mol Biol Rev 68:518-537.

34. Glass JI, Assad-Garcia N, Alperovich N, Yooseph S, Lewis MR, et al. 2006. Essential genes of a minimal bacterium. Proc Nat Acad Sci USA 103:425-430.

35. Chan LY, Kosuri S, Endy D. 2005. Refactoring bacteriophage T7. Mol Sys Biol DOI: $10.1038 / \mathrm{msb} 4100025$

36. Cello J, Paul AV, Wimmer E. 2002. Chemical synthesis of poliovirus cDNA: generation of infectious virus in the absence of natural template. Science 297:1016-1018.

37. Smith HO, Hutchinson CA III, Pfanndoch C, Venter JC. 2003. Generating a synthetic genome by whole genome assembly: $\Theta X 174$ bacteriophage from synthetic oligonucleotides. Proc Natl Acad Sci USA 100:1544015445

38. www.syntheticgenomics.com/about.htm

39. Lartigue C, Glass JI, Alperovich N, Pieper R, Parmar PP, et al. 2007. Genome transplantation in bacteria: changing one species to another. Science 317:632-638

40. Ball P. 2007. Designs for life. Nature 448:32-33.

41. Pennisi E. 2007. Replacement genome gives microbe new identity. Science 316:1827

42. Holt RA, Warren R, Flibotte S, Missirlis PI, Smailus DE. 2007. Rebuilding microbial genomes. BioEssays 29:580-5589.

43. Itaya M, Tsuge K, Koisumi M, Fujita K. 2005. Combining two genomes in one cell: stable cloning of the Synechocystis PCC6803 genome in the Bacillus subtilis 168 genome. Proc Nat Acad Sci USA 102:15971-15976.

44. Glass JI, Smith HO, Hutchinson CA III, Alperovich NY, Assad-Garcia N, (Inventors); J. Craig Venter Institute, Inc. (Assignee). 2007, October 12. Minimal bacterial genome. United States patent application 20070122826

45. www.etcgroup.org/upload/publication/pdf_file2/631.

46. ETC Group. 2007. Extreme genetic engineering: an introduction to synthetic biology www.etcgroup.org/upload/publication/602/01/synbioreportweb.pdf.

47. Cho MK, Magnus D, Caplan AL, McGee D. Ethics of Genomics Group. 1999. Ethical considerations in synthesizing a minimal genome. Science 286:2087-2090

48. J. Craig Venter Institute. 2007. JCVI scientists publish first bacterial genome transplantation changing one species to another (press release) www.jcvi.org/press/news/news_2007_06_28.php.

49. Luisi PL. 2006. The emergence of life: from chemical origins to synthetic biology. Cambridge: Cambridge University Press

50. Deamer D. 2005. A giant step towards artificial life? Trends Biotechnol 23:336-338.

51. Noireaux V, Bar-Ziv R, Godefroy J, Salman H, Libchaber A. 2005. Toward an artificial cell based on gene expression in vesicles. Phys Biol 2 : $1-8$

52. Solé RV, Munteanu A, Rodríguez-Caso C, Macia J. 2007. Synthetic protocell biology: from reproduction to computation. Philos Trans R Soc Lond B Biol Sci (FirstCite) doi:10.1098/rstb.2007.2065.

53. Szostak JW, Bartel DP, Luisi PL. 2001. Synthesizing life. Nature 409 : 387-390.

54. Forster AC, Church GM. 2006. Towards synthesis of a minimal cell. Mol Syst Biol doi:10.1038/msb4100090.

55. Luisi PL, Ferri F. Stano P. 2006. Approaches to semi-synthetic minimal cells: a review. Naturwissenschaften 93:1-13.

56. Benner SA. 2003. Act natural. Nature 421:118.

57. www.protolife.net/company/profile.php.

58. e.g.: www.synthcells.org.

59. http://arep.med.harvard.edu/SBP/Church_Biohazard04c.htm.

60. http://blog-msb.embo.org/blog/2007/06/sb_30_day_2_1.html.

61. Anderson JC, Voigt CA, Arkin AP. 2007. Environmental signal integration by a modular AND gate. Mol Syst Biol 3 Article number 133 doi:10.10138/msb4100173

62. Wolf DM, Arkin AP. 2003. Motifs, modules and games in bacteria. Curr Opin Microbiol 6:125-134.

63. Arkin AP. Fletcher DA. 2006. Fast, cheap and somewhat in control. Genome Biol 7:114 doi:10.1186/gb-2006-7-8-114.

\section{BioEssays 30.1}


64. Stone M. 2006. Life redesigned to suit the engineering crowd. Microbe 1:566-570. www.asm.org/microbe/index.asp?bid=47155

65. www.openwetware.org/wiki/Synthetic_Biology:Abstraction_hierarchy.

66. http://pawsonlab.mshri.on.ca/

67. Ball P. 2005. Synthetic biology for nanotechnology. Nanotechnology 16:R1-R8.

68. Voigt CA. 2007. Genetic parts to program bacteria. Curr Opin Biotechnol 17:548-557.

69. Marguet P, Balagadde P, Tan C, You L. 2007. Biology by design: reduction and synthesis of cellular components and behaviour. J R Soc Interface doi:10.1098/rsif.2006.0206.

70. Luisi PL. 2002. Toward the engineering of minimal living cells. Anat Rec 268:208-214.

71. Pleiss J. 2006. The promise of synthetic biology. Appl Microbiol Biotechnol 73:735-739, p 738.

72. Ferber D. 2004. Microbes made to order. Science 303:158-161.

73. Ball P. 2004. Starting from scratch. Nature 431:624-626.

74. Alon U. 2007. Simplicity in biology. Nature 446:497.

75. Guido NJ, Want X, Adalsteinsson D, McMillen D, Hasty J, et al. 2006. A bottom-up approach to gene regulation. Nature 439:856-860.

76. Murphy KF, Balàzsi G, Collins JJ. 2007. Combinatorial promoter design for engineering noisy gene expression. Proc Natl Acad Sci USA 104 $12726-12731$.

77. Schuber F, Kichler A, Boeckler C, Frisch B. 1998. Liposomes: from membrane models to gene therapy. Pure Appl Chem 70:89-96.

78. Simpson ML. 2006. Cell-free synthetic biology: a bottom-up approach to discovery by design. Mol Syst Biol DOI: 10.1038/msb4100104.

79. Heinemann M, Panke S. 2006. Synthetic biology-putting engineering into biology. Bioinformatics 22:2790-2799 p 2793.

80. Zimmer C. 2006. Scientist of the year: Jay Keasling. Discover Magazine December 2006. http://discovermagazine.com/2006/dec.

81. NEST New and Emerging Science and Technology, European Community, 2005. Synthetic biology: applying engineering to biology.
Brussels: European Commission Directorate General for Research. Available at http://www.univ-poitiers.fr/recherche/documents/pcrdt7/ syntheticbiology.pdf.

82. Breithaupt H. 2006. The engineer's approach to biology. EMBO Rep 7:21-24.

83. Chopra P, Kamma A. 2006. Engineering life through synthetic biology. In Silico Biol 6:401-410.

84. Yokobayashi Y, Weiss R, Arnold FH. 2002. Directed evolution of a genetic circuit. Proc Natl Acad Sci USA 99:16587-16591.

85. McDaniel R, Weiss R. 2005. Advances in synthetic biology: on the path from prototypes to applications. Curr Opin Biotechnol 16:476483.

86. http://media.coe.berkeley.edu/BIOSECURITY/03082007/BioLC8.asx.

87. Tucker JB, Zilinskas RA. 2006. The promise and perils of synthetic biology. New Atlantis 12:25-45

88. Tyo KE, Alper HS, Stephanopoulos GN. 2007. Expanding the metabolic engineering toolbox: more options to engineer cells. Trends Biotech 25:132-137.

89. Doktycz MJ, Simpson ML. 2007. Nano-enabled synthetic biology. Mol Syst Biol 3: Article number 125 DOI: 10.1038/msb4100165.

90. See the bottom of every page of www.syntheticbiology.org.

91. Barrett CL, Kim TY, Kim HU, Palsson BØ, Lee SY. 2006. Systems biology as a foundation for genome-scale synthetic biology. Curr Opin Biotechnol 17:1-5.

92. Kitano H. 2002. Systems biology: a brief overview. Science 295:16621664

93. Rosen R. 1991. Life itself: a comprehensive inquiry into the nature, origin and fabrication of life. NY: Columbia University Press.

94. Cornish-Bowden A. 2006. Putting the systems back into systems biology. Perspect Biol Med 49:475-489.

95. Wolkenhauer O, Hofmeyr J-HS. 2007. An abstract cell model that describes the self-organization of cell function in living systems. J Theor Biol 246:461-476. 